\title{
EDUCAÇÃO: AS PESSOAS E AS COISAS ${ }^{1}$
}

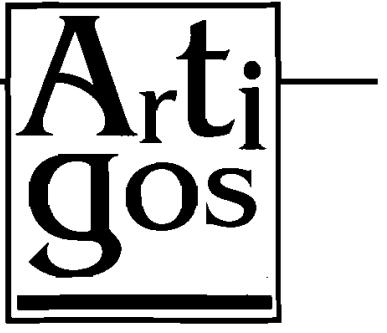

nacionais

\section{O salário do professor oscila de $R \$ 0,50$ a $R \$ 2,00$ a hora/aula, retrato fiel da importância dada à qualidade do ensino no Brasil}

Tenho lido dezenas de estudos recheados de tabelas e gráficos provando à sociedade o que toda gente sabe: a educação básica no Brasil vai muito mal. Na lista dos piores do mundo suplantamos só o Haiti e parece que também Moçambique. A repetência ao longo do primeiro ciclo é altíssima. Quem acompanhou as pesquisas do saudoso Sérgio Costa Ribeiro, mestre em Estatística, está consciente dessa verdadeira praga que vem sendo a reprovação sistemática no ensino primário. E a evasão é fato notório nas primeiras séries.

Depois de muito bater a cabeça à procura das causas de uma situação tão vexatória, os analistas foram descartando, uma a uma, as hipóteses falsas ou frágeis. Lembro duas que ainda são correntes.

Em primeiro lugar, não se trata de falta de vagas nem de prédios escolares ${ }^{2}$. Pelo contrário, há salas ociosas em algumas cidades do interior de São Paulo e dos estados sulinos. Afora os bolsões de miséria do Nordeste rural, o problema das vagas, outrora crônico, deixou de ser agudo, passou a conjuntural. Pode-se dizer, grosso modo, que as crianças brasileiras têm seu lugar nas escolas. O acesso ao primeiro grau foi razoavelmente ampliado nos últimos anos. Logo, in- vestir em construções não deve ser prioridade para nossos governos estaduais e municipais. O conúbio de prefeito e empreiteira seria hoje um conluio.

Outra hipótese aparentemente justa, mas ainda fora do alvo, atribuía o fracasso escolar a fatores extra-educacionais, como a desnutrição dos alunos pobres, ou a baixa qualidade de vida das suas famílias de origem. Trata-se de males reais, sem dúvida, mas, segundo fontes idôneas, os casos de malogro no aprendizado devido à má alimentação da criança não constituem regra geral. A administração da merenda escolar estaria suprindo as deficiências mais graves, o que soa como uma boa nova em meio a tanta desolação. Igualmente a chamada "carência cultural" do meio de onde provém o alunado já não é o bode expiatório que por tanto tempo serviu para justificar, não sem uma ponta de preconceito, a prática da reprovação em massa.

\section{O AUTOR}

\section{Alfredo Bosi}

Professor Titular da Faculdade de Filosofia, Letras e Ciências Humanas da USP, autor, entre outros, de História Concisa da Literatura Brasileira.

1. Publicado originalmente no Jornal do Brasil, 10/02/96, p.7.

2. Ver sobre o assunto: SOARES, Ismar de Oliveira. A televisão e as prioridades da educação. Comunicação \& Educação. São Paulo: CCA-ECA/USP; Moderna, n.6. maio/ago-1996, p.22-28. 
A causa das causas do nosso desastre pedagógico não se acharia portanto nem na falta de prédios e vagas, nem nas condições de saúde, nem na extração cultural das crianças e adolescentes do país.

\section{ONDE IDENTIFICAR O X DA QUESTÃo?}

Entre as quatro paredes da sala de aula. Na relação do professor com a sua profissão. Chegando mais perto: nas mentes e nos corações dos nossos mestres. E para não cair na tentação fácil do idealismo: o nó górdio a ser cortado é o que amarra as condições que o próprio professor leva dentro de si quando exerce o magistério.

Tanto a sociedade civil quanto os aparelhos estatais pensam e agem como se ignorassem este fato cotidiano mas espantoso: o nosso professor primário é remunerado como se fosse um operário não qualificado. $O$ seu salário nada tem a ver com a importância crucial da sua função pública, que é a de primeiro motor do desenvolvimento, nem merece as ácidas cobranças de eficiência que periodicamente lhe fazem a mesma sociedade e o mesmo estado, que o deixaram à míngua.

Tive o cuidado de comparar o vencimento de professores da rede oficial em várias unidades da federação. $O$ docente de primeiro grau, aquele a quem a Nação delega o encargo de ensinar a ler, escrever e contar, ganha, em média, dois reais por aula nas províncias mais bem aquinhoadas do Sudeste e do Sul.

Façamos as contas, o que é sempre mais honesto do que fazer-de-conta que tudo vai bem. Para receber cinco magros salários mínimos, este nosso bóia-fria do giz e da lousa teria que dar em torno de duzentas e cinquienta aulas por mês. Ou seja, teria que cumprir a façanha de trabalhar entre dez e doze horas por dia.

Calculo por médias, mas não escondo extremos afrontosos. Professores há, no Vale do Jequitinhonha, que amargam 40 reais por mês, isto é, 50 centavos por aula. Quanto ao limite superior da amostra: no Rio, em São Paulo e em Belo Horizonte, cidades onde "melhor" se paga ao mestre-escola, a horaaula não vale mais que dois reais e cinquienta centavos. É um salário menos vil, relativamente, mas, absolutamente, sempre vil.

Escolhi o teto de cinco salários mínimos, pois não ousei tocar a soleira dos 763 reais, que representariam aquele quantum necessário para que uma família de quatro pessoas pudesse viver hoje com alguma decência. Louvo-me aqui na estimativa do Dieese, Departamento Intersindical de Estatística e Estudos Sócio-Econômicos.

Temo que este cenário de desvalorização brutal do professor primário não mude tão cedo. Li com interesse o elenco das prioridades com que o governo pretende enfrentar o desafio da educação básica. Não discuto intenções. Apenas constato o primado das coisas sobre as pessoas. Computadores aos milhares sem professores prezados e estimulados são sucata virtual. Livros didáticos sem mestres que os leiam e os interpretem com garra e entusiasmo são pilhas de papéis destinados ao lixo do esquecimento. Quanto às avaliações severas prometidas (tremam os relapsos afundados nos seus pingues proventos!), supõem um longo tempo de experiência em condições humanas de trabalho.

As pessoas, quando respeitadas no seu ofício, produzem sentido e valor. Com ou sem as coisas. Mas as coisas sem as pessoas são letra morta. Preferir coisas a pessoas não é realismo. É apenas conformismo. 
Resumo: A baixa qualidade de ensino e o alto nível de repetência não têm como causa, na atualidade, a falta de vagas nas escolas. Estão ligadas, na verdade, às condiçōes de trabalho oferecidas, pelo Estado, aos professores: longas jornadas e péssimos salários.

Palavras-chave: educaçāo, professores, repetência, salários.
Abstract: The low quality of education and the high level of failures are not due nowadays to lack of vacancies in schools. But they are connected with the working conditions given by the Government to the teachers: long hours and low salaries.

Key-words: education, teachers, failures, salaries.

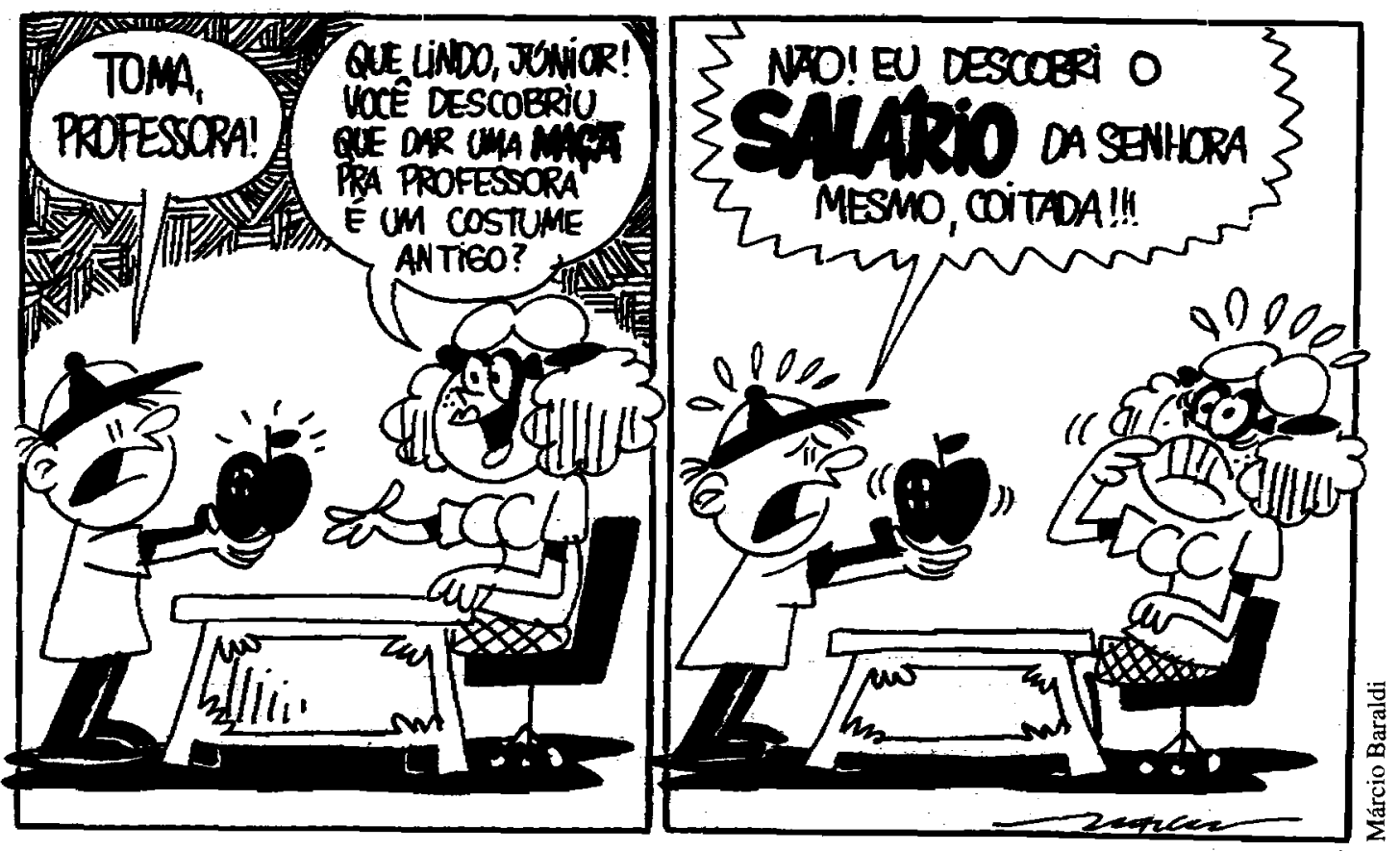

